\title{
Association of the PPARY2 Pro12Ala polymorphism with increased risk of cardiovascular diseases
}

\author{
Y. Li ${ }^{1 *}$, J. Zhü and J.Q. Ding ${ }^{3}$ \\ 1'Department of Pharmacy, Ministry of Health Beijing Hospital, Beijing, China \\ ${ }^{2}$ Medical Department, Henan Provincial Corps Hospital of The Chinese People's \\ Armed Police Force, Zhengzhou, China \\ ${ }^{3}$ Department of Pharmacy, Henan Provincial Corps Hospital of the Chinese \\ People's Armed Police Force, Zhengzhou, China \\ ${ }^{*}$ These authors contributed equally to this study. \\ Corresponding author: J.Q. Ding \\ E-mail: dingjianqiang222@163.com
}

Genet. Mol. Res. 14 (4): 18662-18674 (2015)

Received April 16, 2015

Accepted July 2, 2015

Published December 28, 2015

DOI http://dx.doi.org/10.4238/2015.December.28.15

ABSTRACT. This meta-analysis investigated the correlation between the PPARY2 Pro12Ala polymorphism and cardiovascular disease (CVD). Electronic database and manual searches were conducted to retrieve studies published relevant to the PPARY2 Pro12Ala polymorphism and CVD. Rigorous inclusion and exclusion criteria were employed for selection of high-quality patients-control studies. Statistical data analyses on allelic, dominant, homozygous, heterozygous, and recessive inheritance models were performed using the R 3.1 .0 and Stata 12.0 software. We enrolled 12 case-control studies consisting of 10,189 patients with CVD [1070 with myocardial infarction (MI), 7849 with coronary artery disease (CAD), and 1270 with acute coronary syndromes (ACS)] and 17,899 controls. The results of meta-analyses revealed that the PPARY2 Pro12Ala (rs1801282) polymorphism was correlated with a higher risk of CVD under both allelic and dominant models, while no statistical significance was found under 
homozygous, heterozygous, or recessive models. Subgroup analysis based on disease showed that the PPARY2 Pro12Ala (rs1801282) polymorphism was correlated with a higher risk of $\mathrm{MI}$ under both allelic and dominant models, while no statistical significance was found for association with CAD or ACS under allele or dominant models. Furthermore, under homozygous, heterozygous, and recessive models, the PPARy2 Pro12Ala (rs1801282) polymorphism had no statistically significant association with $\mathrm{MI}, \mathrm{CAD}$, or ACS. The results of this meta-analysis suggest that the PPARY2 Pro12Ala (rs1801282) polymorphism might be correlated with a higher risk of CVD, particularly MI, and could serve as an important early indicator for CVD.

Key words: Cardiovascular disease; PPARY2; Polymorphism; Gene; Meta-analysis; Coronary artery disease

\section{INTRODUCTION}

Cardiovascular diseases (CVDs) refer to diseases affecting the cardiovascular system, and primarily involve cardiac disease, peripheral arterial disease, and vascular diseases of the brain and kidney (Fuster and Kelly, 2010). CVD is one of the leading causes of disability and death in western societies (Leening et al., 2014). By 2030, approximately 40.5\% of Americans are projected to have some form of CVD (Perk et al., 2012). Current data show that $80 \%$ of deaths caused by CVD occur in under-developed and developing countries and that the death rates have increased steeply in these countries in the last decade (Smith et al., 2012; Finegold et al., 2013). Aside from the common risk factors such as age, gender, and air pollution, genetic variations have been suspected to play an important role in CVD risks as well (International Consortium for Blood Pressure Genome-Wide Association et al., 2011; Marian and Belmont, 2011). For example, polymorphisms in CYP2C19, tissue factor, and C-reactive protein have been documented to be associated with predisposition to CVD or to influence treatment outcomes (Mega et al., 2011; Emerging Risk Factors Collaboration et al., 2012). In this light, peroxisome proliferator-activated receptors (PPARs) are among the most promising therapeutic targets in CVD (van Bilsen and van Nieuwenhoven, 2010).

PPARs belong to the superfamily of nuclear receptors and have three isoforms (alpha, beta/ delta, and gamma) capable of regulating glucose homeostasis, local immune responses, lipoprotein metabolism, local inflammation, thrombosis, tumor development, and which are believed to have potential antiatherogenic effects (Fisman and Tenenbaum, 2009; Wahli and Michalik, 2012). Of the 3 isoforms, PPARy, a ligand-activated transcription factor, functions as the master regulator of fat storage, and is expressed in vascular smooth muscle cells, monocytes/macrophages, endothelial cells, and T-cells (Galgani et al., 2010). The PPARY gene has been mapped to chromosome 3 p25 and contains six exons. The most common polymorphism in PPARY is a cytosine-guanine variation located in exon $B$, which results in a proline to alanine (Pro12Ala) substitution in codon12 of the protein (Beamer et al., 1997; Wu et al., 2012). The human PPARy2 isoform contains an extra 28 amino acids at its $\mathrm{N}$-terminus, and is exclusively expressed in adipocytes (Beamer et al., 1997; van Bilsen and van Nieuwenhoven, 2010). Recently, the relationship between the PPARY2 polymorphism and CVD has been extensively researched (Azhar, 2010; Wang et al., 2012). Previous studies have shown that the Pro12Ala polymorphism of the PPARY2, in homozygous or heterozygous conditions, might lead to an increased risk of coronary heart disease (CHD) (Dallongeville et al., 2009; Ho et al., 2012). Similarly, coronary artery disease (CAD) risk has also 
been linked to this polymorphism (Wu et al., 2012). In contrast, a study in a Korean population could not find an association between the Pro12Ala polymorphism of PPARY and CAD, and another study demonstrated that homozygosity for the Ala allele of the PPARY2 Pro12Ala polymorphism is more strongly linked with a decreased risk of CAD (Rhee et al., 2007; Galgani et al., 2010). In order to address the conflicting results from previous studies, we designed this study to investigate the correlation between the PPARY2 Pro12Ala polymorphism and CVD.

\section{MATERIAL AND METHODS}

\section{Data sources and search strategy}

We searched for studies related to the PPARY2 Pro12Ala polymorphism and CVDs published prior to October 2014 and in the English or Chinese language. The electronic databases PubMed, EBSCO, Ovid, Springerlink, Wiley, Web of Science, Wanfang Database, China National Knowledge Infrastructure, and VIP were searched to retrieve relevant literature. The following free text words and key words were used as search terms: peroxisome proliferator activated receptor-y2 (PPARY2), cardiovascular disease, circulatory system diseases, coronary heart disease CHD, coronary artery disease (CAD), pectoris, myocardial infarction (MI), and genetic polymorphism. A manual search was also employed to identify additional articles from cross-references.

\section{Eligibility criteria}

The study inclusion criteria were: 1) case-control design, 2) consisted of patients with CVD and healthy controls as study subjects, and 3) included outcomes of alleles and genotype frequencies in both patient and control groups. In cases of overlapping publications, only the latest study or that with the largest sample size was selected. The exclusion criteria were: 1) abstracts and reviews; 2) animal studies; 3 ) repeated publications or unpublished studies; and 4) incomplete data.

\section{Data extraction}

Data were independently extracted from the selected studies and assessed by two reviewers (Y.L. and J.Z.). The extracted information included: first author's name, country, year of publication, ethnicity, language, disease, age, gender, number of patients and controls, genotyping methods, study design, and single nucleotide polymorphism. In the case of disagreement between the two reviewers, a third investigator was consulted to arrive at a consensus decision. Quality assessment of the data was performed by two investigators (J.Z. and J.Q.D.), using the National Health Service Critical Appraisal Skills Programme (CASP) Checklists (http://www.casp-uk.net/). Specifically, the checklists included the following questions: 1) whether a clearly focused issue was addressed (CASP01); 2) whether the authors answered their questions using an appropriate method (CASP02); 3) whether the patients were recruited in an acceptable way (CASP03); 4) whether the controls were selected in an acceptable way (CASP04); 5) whether the exposure was accurately measured to minimize bias (CASP05); 6) whether the authors had taken account of the potential confounding factors in the design and/or in their analyses (CASP06); 7) what were the results of this study (CASP07); 8) how precise were the results (CASP08); 9) whether the results were credible (CASP09); 10) whether the results could be applied to the local population (CASP10); and 11) whether the results of this study fit with other available evidence (CASP11). 


\section{Statistical analysis}

The R 3.1.0 (Robert Gentleman and Ross Ihaka, Auckland University, New Zealand) and the STATA 12.0 software (Stata Corporation, College Station, TX, USA) programs were applied for statistical analyses. To explore the associations between the PPARY2 Pro12Ala polymorphism and CVDs, the odds ratios (ORs) at $95 \% \mathrm{Cls}$ were assessed using a fixed-effect or random-effect model. A Z test (Chen et al., 2012) was carried out to assess the significance of the overall effect size and forest plots were used to display the values of OR at $95 \% \mathrm{Cls}$ between patient and control groups. Heterogeneity was assessed by the Cochran's Q-statistic (Chen et al., 2012), with P < 0.05 indicating the existence of heterogeneity. For quantification of the degree of heterogeneity, the I-squared $\left(I^{2}\right)$ statistic (Peters et al., 2006) was calculated ranging from 0 to $100 \%(0 \%$, no heterogeneity; $100 \%$, maximal heterogeneity). A random-effect model was used when the studies were assumed to be heterogeneous ( $\mathrm{P}<0.05$ or $l^{2}>50 \%$ ), otherwise a fixed-effect model was used (Zintzaras and loannidis, 2005). We estimated the source of heterogeneity by univariate and multivariate meta-regression analyses, and further verification was conducted using Monte Carlo simulation (Ferrenberg and Swendsen, 1988; Huizenga et al., 2011; Jackson et al., 2012). Sensitivity analysis of the variables was performed to assess the influence of one single study on the overall outcomes. Funnel plots and an Egger test (Egger et al., 1997) were performed for the assessment of publication bias to evaluate the reliability of the results.

\section{RESULTS}

\section{Overview of the study characteristics}

A total of 290 relevant articles were initially retrieved from database searches and 20 were excluded for being duplicates. Other articles were screened out as follows: letters, reviews, and meta-analyses $(\mathrm{N}=4)$, non-human studies $(\mathrm{N}=75)$, articles not related to the research topics $(\mathrm{N}$ = 62), not case-control or cohort studies $(N=20)$, irrelevant to CVD $(N=59)$, irrelevant to PPARY2 $(\mathrm{N}=37)$, and not in conformity with Hardy-Weinberg equilibrium (HWE) $(\mathrm{N}=1)$. In the end, a total of 12 relevant case-control studies, published between 2004 and 2013, were included in this metaanalysis, involving 10,189 patients with CVD and 17,899 controls (Tobin et al., 2004; Nassar et al., 2006; Zee et al., 2006; Rhee et al., 2007; Ruiz-Narváez et al., 2007; Dallongeville et al., 2009; Vogel et al., 2009; AshokKumar et al., 2010; Galgani et al., 2010; Yilmaz-Aydogan et al., 2011; Ho et al., 2012; Youssef et al., 2013). The sample sizes ranged from 300-9758 and included 1070 patients with MI, 7849 with CAD, and 1270 with acute coronary syndromes (ACS). Of the 12 eligible studies, 3 were based on Asian population, 8 on Caucasians, and 1 was based on Africans. A flow chart for study selection is presented in Figure 1. The baseline characteristics of these studies are presented in Table 1. CASP assessments for each included study are summarized in Figure 2.

\section{Meta-analysis results}

Significant heterogeneity was found in the cases of allelic, dominant, and heterozygous models (allelic model: $I^{2}=80.8 \%, \mathrm{P}<0.0001$; dominant model: $I^{2}=84.7 \%, \mathrm{P}<0.0001$; heterozygous model: $I^{2}$ $=82.3 \%, \mathrm{P}<0.0001$ ); thus, a random-effect model was employed. Homozygous and recessive models showed no significant heterogeneity (homozygous model: $I^{2}=32.5 \%, \mathrm{P}=0.1308$; recessive model: $l^{2}=$ $27.8 \%, P=0.1719$ ); hence, a fixed-effect model was applied (Figure 3A, C, E, G, and I). 


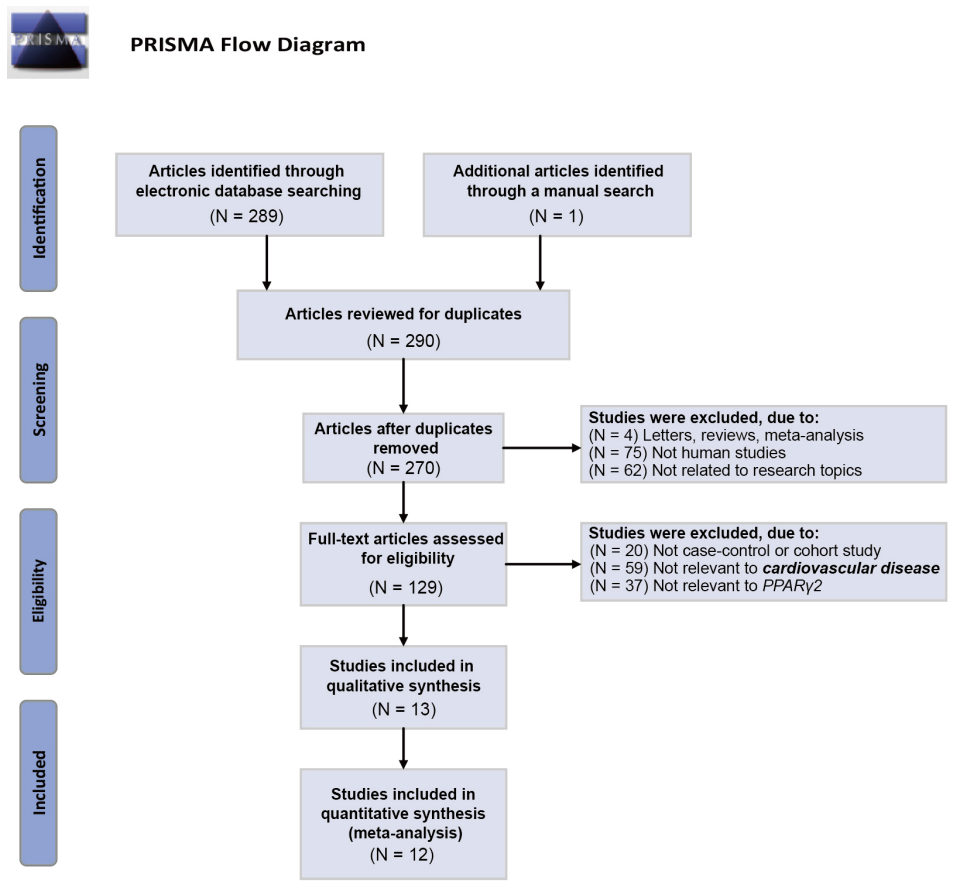

Figure 1. Flow chart for selection of studies for inclusion in this meta-analysis.

\begin{tabular}{|c|c|c|c|c|c|c|c|c|c|c|c|}
\hline & 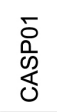 & $\begin{array}{l}0 \\
0 \\
00 \\
0 \\
0\end{array}$ & $\begin{array}{l}0 \\
0 \\
0 \\
0 \\
0 \\
0\end{array}$ & $\begin{array}{l}\text { d } \\
\text { 0. } \\
\text { 王 }\end{array}$ & $\begin{array}{l}0 \\
00 \\
03 \\
0 \\
0\end{array}$ & $\begin{array}{l}0 \\
00 \\
01 \\
0 \\
0\end{array}$ & $\begin{array}{l}\hat{0} \\
0 \\
0 \\
0 \\
0\end{array}$ & $\begin{array}{l}\text { o } \\
0 \\
0 \\
0 \\
0\end{array}$ & 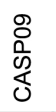 & $\begin{array}{l}\frac{0}{0} \\
0 \\
\frac{1}{0} \\
0\end{array}$ & $\begin{array}{l}\frac{0}{0} \\
\frac{1}{0}\end{array}$ \\
\hline Tobin MD (2004) & + & $\odot$ & $\odot$ & $?$ & $\odot$ & + & $\odot$ & + & $\odot$ & + & + \\
\hline Nassar BA (2006) & + & $\odot$ & $\odot$ & $\odot$ & $\odot$ & + & $\odot$ & + & $\odot$ & $\odot$ & + \\
\hline Zee RY (2006) & + & + & + & $\odot$ & + & + & $\odot$ & + & + & $?$ & + \\
\hline Rhee EJ (2007) & + & $\odot$ & + & $\odot$ & $?$ & + & $?$ & + & + & + & + \\
\hline iz-Narvaez EA (2007) & + & + & + & + & + & $?$ & + & + & + & + & 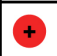 \\
\hline Dallongeville $\mathrm{J}$ & + & + & + & + & $\odot$ & $?$ & + & + & + & + & + \\
\hline Vogel U & + & + & $\odot$ & $\odot$ & $\odot$ & + & $\odot$ & + & $\odot$ & + & + \\
\hline AshokKumar M (2010) & + & + & + & $\odot$ & $\odot$ & $?$ & + & + & $\odot$ & + & + \\
\hline Galgani A & + & + & + & $?$ & + & + & + & + & $\odot$ & $?$ & + \\
\hline naz-Aydogan ! & + & $\odot$ & + & $?$ & $?$ & + & + & + & + & + & + \\
\hline Ho JS (2 & + & + & $\odot$ & + & $\odot$ & $?$ & + & + & + & + & 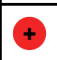 \\
\hline Youssef SM & + & + & \begin{tabular}{|l|}
+ \\
\end{tabular} & $\odot$ & ? & + & + & + & + & + & + \\
\hline
\end{tabular}

Figure 2. National Health Service Critical Appraisal Skills Program assessments for each study included. 


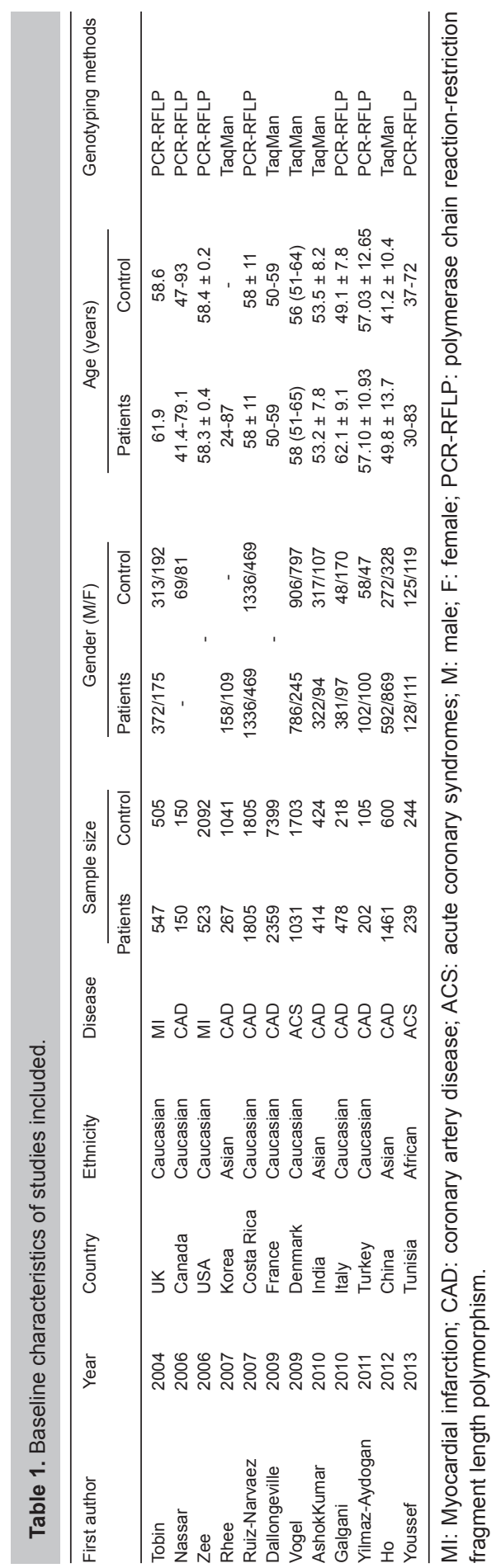


Meta-analysis results revealed that the PPARY2 Pro12Ala polymorphism conferred a higher risk of CVD under both allelic and dominant models (allelic model: $\mathrm{OR}=0.80,95 \% \mathrm{Cl}$ $=0.66-0.98, \mathrm{P}=0.040$; dominant model: $\mathrm{OR}=0.74,95 \% \mathrm{Cl}=0.58-0.95, \mathrm{P}=0.033$ ), while no statistical significance was observed under either homozygous, heterozygous, or recessive models (homozygous model: $\mathrm{OR}=0.98,95 \% \mathrm{Cl}=0.73-1.31, \mathrm{P}=0.888$; heterozygous model: $\mathrm{OR}=0.75$, $95 \% \mathrm{Cl}=0.59-1.05, \mathrm{P}=0.703$; and recessive model: $\mathrm{OR}=1.00,95 \% \mathrm{Cl}=0.75-1.33, \mathrm{P}=0.980$ ) (Figure 3A, C, E, G, I, and Table 2).

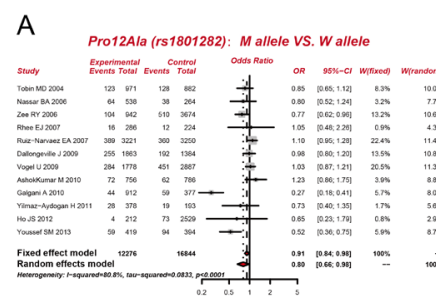

B Pro12Ala (rs1801282): Mallele vS. Wallele
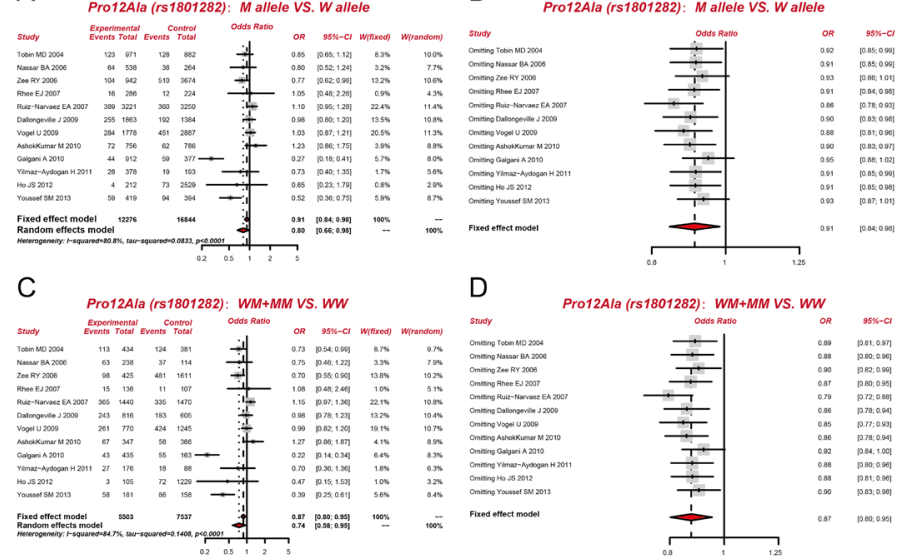

D Pro12Ala (rs 1801282): WM+MM VS. WW
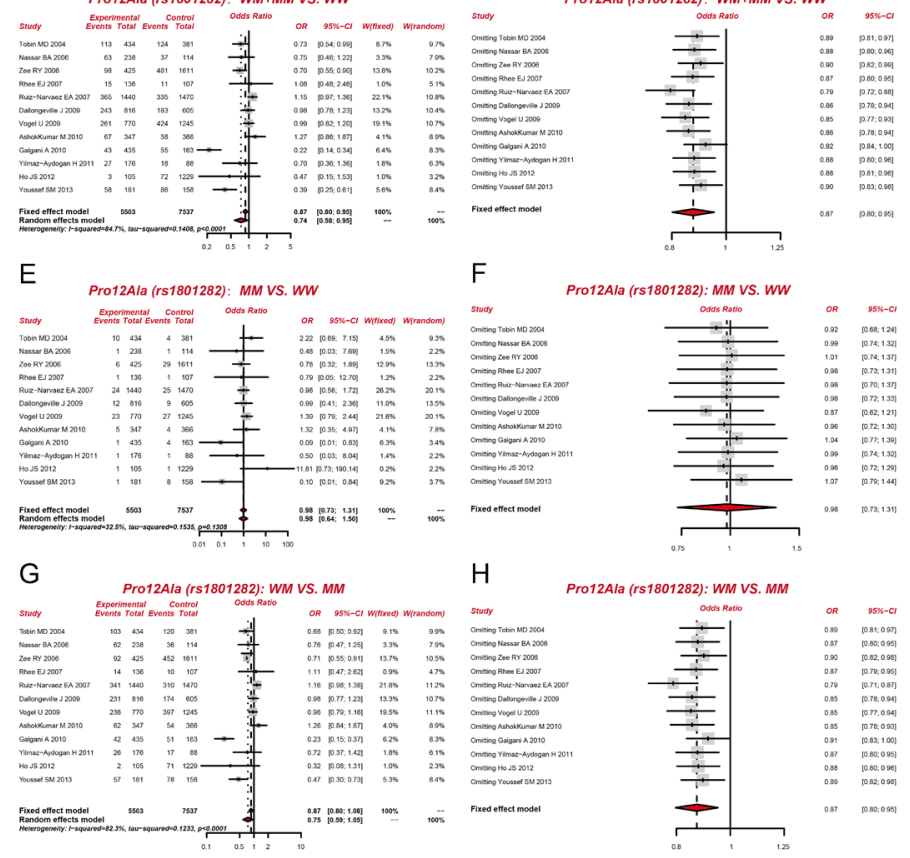

H Pro12Ala (rs1801282): WM vS. MM

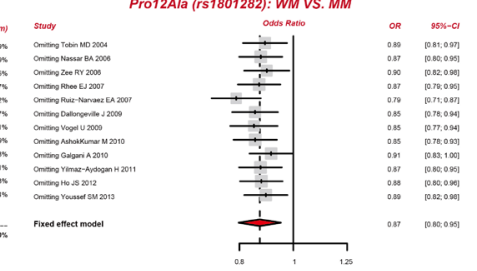

(
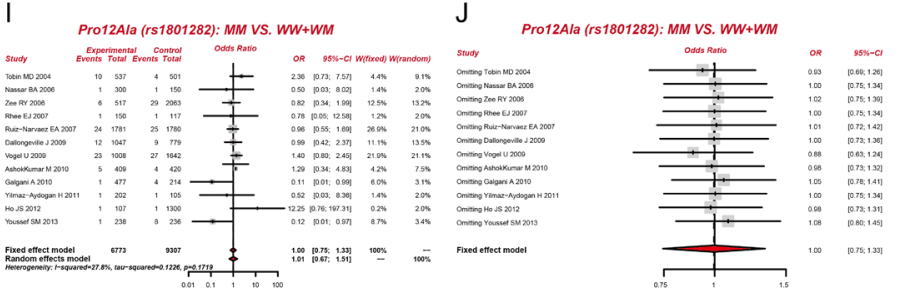

Figure 3. Forest plots and sensitivity analysis on the associations between PPARY2 Pro12Ala polymorphism and cardiovascular diseases. 


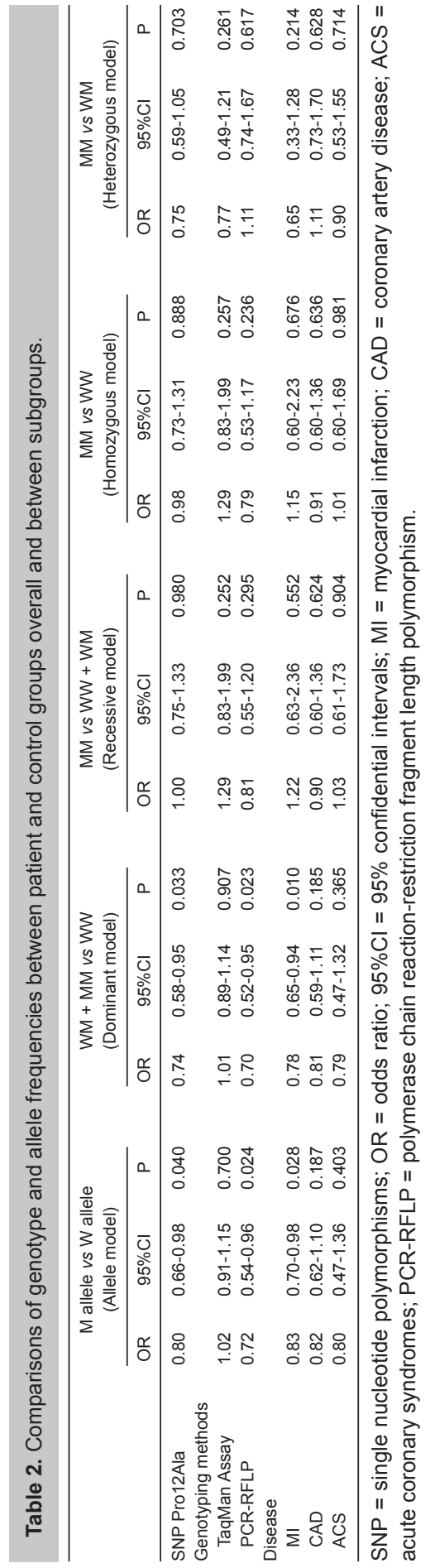


Subgroup analyses based on disease type showed that the PPARY2 Pro12Ala (rs1801282) polymorphism might be correlated with a higher risk of MI under allelic and dominant models, while no statistical significance was found in the case of CAD and ACS under these models (allelic model: $\mathrm{MI}$ OR $=0.83,95 \% \mathrm{Cl}=0.70-0.98, \mathrm{P}=0.028 ; \mathrm{CAD}$ OR $=0.82,95 \% \mathrm{Cl}=0.62-1.10, \mathrm{P}=$ $0.187 ;$ ACS OR $=0.80,95 \% \mathrm{Cl}=0.47-1.36, \mathrm{P}=0.403$; dominant model: $\mathrm{MI}$ OR $=0.78,95 \% \mathrm{Cl}$ $=0.65-0.94, \mathrm{P}=0.010 ; \mathrm{CAD} O \mathrm{OR}=0.81,95 \% \mathrm{Cl}=0.59-1.11, \mathrm{P}=0.185 ; \mathrm{ACS} \mathrm{OR}=0.79,95 \% \mathrm{Cl}$ $=0.47-1.32, \mathrm{P}=0.365)$. Under homozygous, heterozygous, and recessive models, the PPARy2 Pro12Ala (rs1801282) polymorphism presented no statistically significant association with MI, CAD, or ACS (all P > 0.05) (Figure 2).

Further subgroup analyses by genotyping method suggested that the polymerase chain reaction-restriction fragment length polymorphism (PCR-RFLP) method showed statistical significance under both allelic and dominant models (allelic model: $\mathrm{OR}=0.72,95 \% \mathrm{Cl}=0.54-0.96$, $\mathrm{P}=0.024$; dominant model: $\mathrm{OR}=0.70,95 \% \mathrm{Cl}=0.52-0.95, \mathrm{P}=0.023$ ); however, this significance was not found under homozygous, heterozygous, or recessive models (all $P>0.05$ ). On the other hand, the TaqMan assay did not show any statistical significance under the allelic, dominant, homozygous, heterozygous, or recessive models tested (all P >0.05) (Table 2). Based on univariate and multivariate meta-regression analyses, year of publication, ethnicity, disease, and genotyping method were neither the main potential sources of heterogeneity nor the key factors of overall effect size (all P > 0.05) (Figure 4 and Table 3).

A

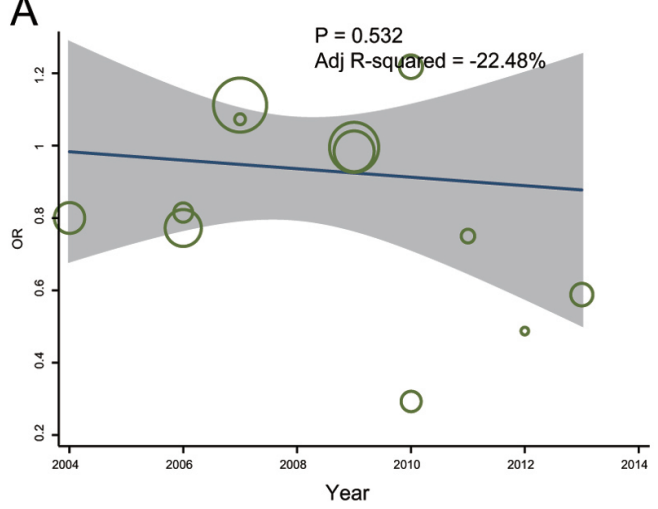

C

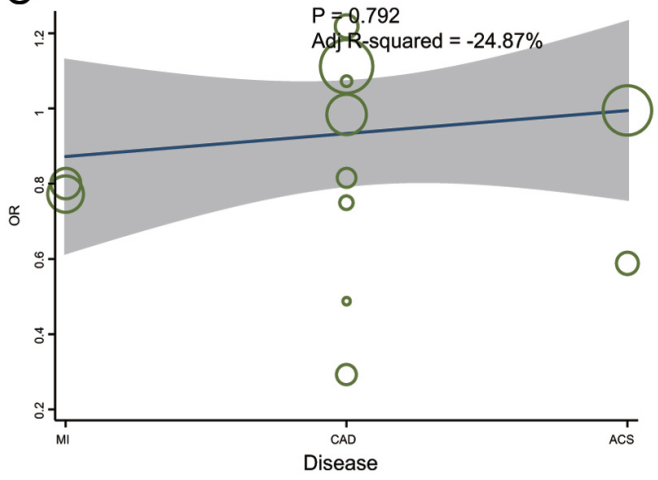

B

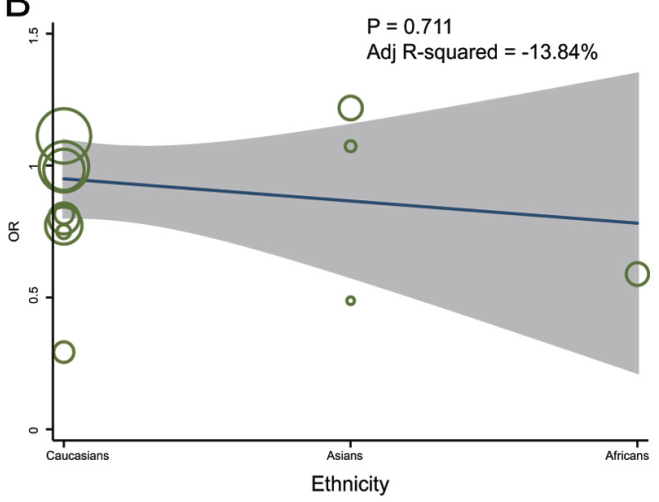

$\mathrm{D}$

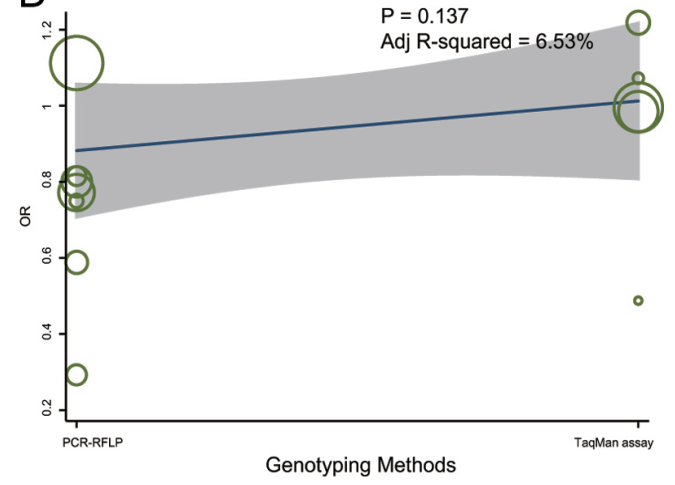

Figure 4. Meta-regression analyses on year of publication, ethnicity, disease, and genotyping method. 


\begin{tabular}{|c|c|c|c|c|c|c|}
\hline \multirow[t]{2}{*}{ Heterogeneity factors } & \multirow[t]{2}{*}{ Coefficient } & \multirow[t]{2}{*}{ SE } & \multirow[t]{2}{*}{$\mathrm{t}$} & \multirow[t]{2}{*}{$\mathrm{P}$ (Adjusted) } & \multicolumn{2}{|c|}{$95 \% \mathrm{Cl}$} \\
\hline & & & & & LL & UL \\
\hline Year & -0.073 & 0.055 & -1.34 & 0.544 & -0.202 & 0.056 \\
\hline Ethnicity & 0.080 & 0.167 & 0.48 & 0.972 & -0.315 & 0.475 \\
\hline Disease & 0.106 & 0.176 & 0.60 & 0.930 & -0.309 & 0.521 \\
\hline Genotyping methods & 0.293 & 0.175 & 1.68 & 0.387 & -0.120 & 0.706 \\
\hline
\end{tabular}

SE = standard error; LL = lower limit; UL = upper limit.

\section{Sensitivity analysis and publication bias}

The results of sensitivity analysis demonstrated that after removal of single studies, the pooled OR values of the remainder were 0.91 under the allelic model, all approximately 0.87 under the dominant model, all approximately 0.98 under homozygous models; all approximately 0.87 under heterozygous models, and under recessive models, the values were all about 1.00 . No significant differences were found among all the data, indicating that our meta-analysis was stable and reliable (Figure 3B, D, F, H, and J). Funnel plots suggested that there were no publication biases under allelic, dominant, homozygous, heterozygous, or recessive models (all P>0.05) (Figure 5A, C, E, G, and I). In addition, the Egger test also revealed no publication bias (Figure $5 \mathrm{~B}, \mathrm{D}, \mathrm{F}, \mathrm{H}$, and J).
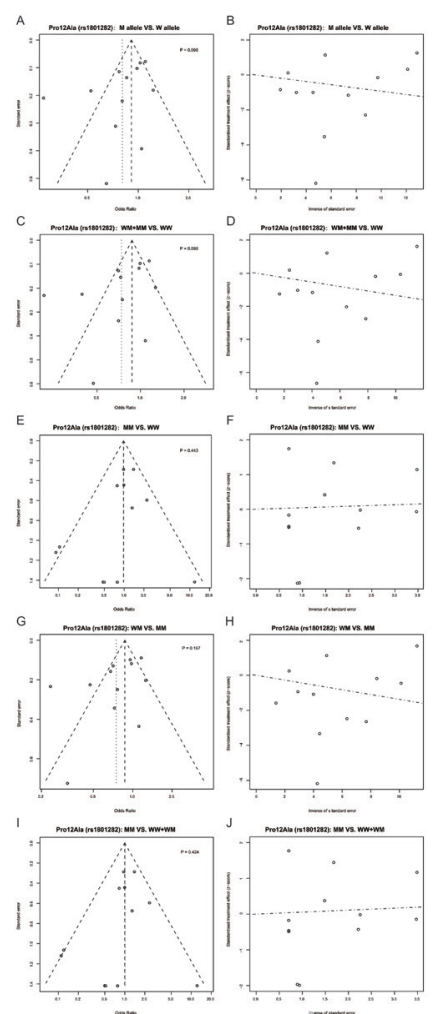

Figure 5. Funnel plot of publication biases on the associations between PPARY2 Pro12Ala polymorphism and cardiovascular diseases. 


\section{DISCUSSION}

PPARy is expressed predominantly in adipose tissue and is a master regulator of lipoprotein metabolism, glucose homeostasis, and vascular homeostasis (Wang, 2010; Yilmaz-Aydogan et al., 2011). The two isoforms of PPAR $y$ ( $\gamma 1$ and $\gamma 2)$ differ at their N-terminus, and the PPARy2 isoform is specific to adipose tissue (Shi et al., 2014). The most common genetic polymorphism in the human PPARy2 gene is a cytosine-guanine exchange in exon $B$ (codon 12), which results in a Pro12Ala substitution in the protein, and carriers of Ala12, which is a common variant, have high fatty acids accumulation in adipose tissue (Xu et al., 2013; Fernández-Rodríguez et al., 2014). The Ala12 variant leads to an amino acid substitution in the ligand-independent activation domain and has been shown to be correlated with decreased transcriptional activity, higher insulin sensitivity, and lower body mass index compared with the wild-type Pro12 allele (Yilmaz-Aydogan et al., 2011). Previous studies have investigated the correlation between the PPARY2 Pro12Ala polymorphism and CAD, but results have remained conflicting (Rhee et al., 2007; Dallongeville et al., 2009; Galgani et al., 2010; Ho et al., 2012; Wu et al., 2012). Therefore, we carried out this meta-analysis to further explore the correlation between the PPARY2 Pro12Ala polymorphism and the risks of CVD, and we found that the PPARY2 Pro12Ala polymorphism under both allelic and dominant models is clearly associated with an increased risk of CVD. Our results further showed that the PPARY2 Pro12Ala polymorphism might increase the severity of several cardiovascular risk factors including obesity and diabetes, and thus, might have a direct effect on CVD outcomes.

PPARy regulates insulin sensitivity and modulates the activity of adiponectin (Tian et al., 2013). Evidence has suggested that the activation of PPARy by thiazolidinedione antidiabetic drugs can result in a higher uptake of fatty acids by adipocytes with the subsequent lowering of circulating free fatty acids, which can mediate many adverse metabolic effects, most notably insulin resistance (Ruiz-Narváez et al., 2007; Karpe et al., 2011). PPARY and adiponectin respond to glucose influx and promote glucose utilization and fatty acid oxidation in muscle (Ho et al., 2012). Differential flux of fatty acids through adipocytes caused by the Pro12Ala polymorphism could increase the risks of type 2 diabetes and CHD (Ruiz-Narváez et al., 2007). Therefore, the Pro12Ala polymorphism might result in reduction of the effect of PPARY on regulation of insulin sensitivity and adiponectin activity, and thus might lead to insulin resistance and glucose tolerance, which eventually would be likely to lead to the occurrence of several CVDs such as hypertension and CHD. On the other hand, the study reported by Rhee et al (2007) concluded that the PPARY Pro12Ala polymorphism had no significant association with CAD or with cardiovascular risk factors in a Korean population. This might be attributed to ethnic factors and to the relatively small sample size in that study. Hence, in order to thoroughly understand the underlying defect caused by the polymorphism and the mechanisms by which it could lead to CVD, the results of epidemiological studies need to be supported by extensive experimental evidence.

Subgroup analysis by disease demonstrated that under allelic and dominant models, the PPARY2 Pro12Ala polymorphism might associate with an increased risk of MI, while no significant correlations of PPARY2 Pro12Ala polymorphism with CAD and ACS were observed. These varying results might be caused by the relatively small sample size in some enrolled studies; therefore, the correlations of the PPARY2 Pro12Ala polymorphism with CAD and ACS need to be further confirmed with a larger sample size. Subgroup analysis based on genotyping method suggested that the different genotyping methods might also influence the overall result of this meta-analysis.

There are some limitations in this study. First, the TT genotype of the Pro12Ala polymorphism was rarely observed in this analysis, which would likely influence the overall results of the present 
study to some extent. Second, the different genotyping methods including PCR-RFLP and TaqMan assays used in enrolled studies might affect the accuracy of the genotyping results.

In conclusion, we found that the PPARY2 Pro12Ala polymorphism could increase the risk of CVD under allelic and dominant models, suggesting that the PPARY2 Pro12Ala polymorphism could be an important indicator of early CVD.

\section{Conflicts of interest}

The authors declare no conflict of interest.

\section{ACKNOWLEDGMENTS}

We would like to express our appreciation to our instructors and to the reviewers for their valuable advice and comments on this article.

\section{REFERENCES}

AshokKumar M, Veera Subhashini NG, Kanthimathi S, SaiBabu R, et al. (2010). Associations for lipoprotein lipase and peroxisome proliferator-activated receptor-gamma gene and coronary artery disease in an Indian population. Arch. Med. Res. 41: 19-25 e1.

Azhar S (2010). Peroxisome proliferator-activated receptors, metabolic syndrome and cardiovascular disease. Future Cardiol. 6: 657-691.

Beamer BA, Negri C, Yen CJ, Gavrilova O, et al. (1997). Chromosomal localization and partial genomic structure of the human peroxisome proliferator activated receptor-gamma (hPPAR gamma) gene. Biochem. Biophys. Res. Commun. 233: 756-759.

Chen $\mathrm{H}$, Manning AK and Dupuis J (2012). A method of moments estimator for random effect multivariate meta-analysis. Biometrics 68: 1278-1284.

Dallongeville J, Iribarren C, Ferrières J, Lyon L, et al. (2009). Peroxisome proliferator-activated receptor gamma polymorphisms and coronary heart disease. PPAR Res. 2009: 543746.

Egger M, Davey Smith G, Schneider M and Minder C (1997). Bias in meta-analysis detected by a simple, graphical test. BMJ 315: 629-634.

Emerging Risk Factors Collaboration, Kaptoge S, Di Angelantonio E, Pennells L, et al. (2012). C-reactive protein, fibrinogen, and cardiovascular disease prediction. N. Engl. J. Med. 367: 1310-1320.

Fernández-Rodríguez A, Berenguer J, Rallón N, Jiménez-Sousa MA, et al. (2014). PPARgamma2 Pro12Ala polymorphism is associated with sustained virological response in HIV/HCV-coinfected patients under HCV therapy. J. Acquir. Immune Defic. Syndr. 67: 113-119.

Ferrenberg AM and Swendsen RH (1988). New Monte Carlo technique for studying phase transitions. Phys. Rev. Lett. 61: 2635-2638.

Finegold JA, Asaria P and Francis DP (2013). Mortality from ischaemic heart disease by country, region, and age: statistics from World Health Organisation and United Nations. Int. J. Cardiol. 168: 934-945.

Fisman EZ and Tenenbaum A (2009). A cardiologic approach to non-insulin antidiabetic pharmacotherapy in patients with heart disease. Cardiovasc. Diabetol. 8: 38.

Fuster V and Kelly BB (2010). Promoting cardiovascular health in the developing world: a critical challenge to achieve global health. The National Academies Collection: Reports funded by National Institutes of Health, Washington, DC.

Galgani A, Valdes A, Erlich HA, Mano C, et al. (2010). Homozygosity for the Ala allele of the PPARgamma2 Pro12Ala polymorphism is associated with reduced risk of coronary artery disease. Dis. Markers 29: 259-264.

Ho JS, Germer S, Tam CH, So WY, et al. (2012). Association of the PPARG Pro12Ala polymorphism with type 2 diabetes and incident coronary heart disease in a Hong Kong Chinese population. Diabetes Res. Clin. Pract. 97: 483-491.

Huizenga HM, Visser I and Dolan CV (2011). Testing overall and moderator effects in random effects meta-regression. Br. J. Math. Stat. Psychol. 64: 1-19.

International Consortium for Blood Pressure Genome-Wide Association Studies, Ehret GB, Munroe PB, Rice KM, et al. (2011). Genetic variants in novel pathways influence blood pressure and cardiovascular disease risk. Nature 478: 103-109.

Jackson D, White IR and Riley RD (2012). Quantifying the impact of between-study heterogeneity in multivariate metaanalyses. Stat. Med. 31: 3805-3820. 
Karpe F, Dickmann JR and Frayn KN (2011). Fatty acids, obesity, and insulin resistance: time for a reevaluation. Diabetes 60: 2441-2449.

Leening MJ, Ferket BS, Steyerberg EW, Kavousi M, et al. (2014). Sex differences in lifetime risk and first manifestation of cardiovascular disease: prospective population based cohort study. BMJ 349: g5992.

Marian AJ and Belmont $\mathrm{J}$ (2011). Strategic approaches to unraveling genetic causes of cardiovascular diseases. Circ. Res. 108: $1252-1269$.

Mega JL, Hochholzer W, Frelinger AL 3rd, Kluk MJ, et al. (2011). Dosing clopidogrel based on CYP2C19 genotype and the effect on platelet reactivity in patients with stable cardiovascular disease. JAMA 306: 2221-2228.

Nassar BA, Rockwood K, Kirkland SA, Ransom TP, et al. (2006). Improved prediction of early-onset coronary artery disease using APOE epsilon4, BChE-K, PPARgamma2 Pro12 and ENOS T-786C in a polygenic model. Clin. Biochem. 39: $109-114$.

Perk J, De Backer G, Gohlke H, Graham I, et al. (2012). European Guidelines on cardiovascular disease prevention in clinical practice (version 2012): The Fifth Joint Task Force of the European Society of Cardiology and Other Societies on Cardiovascular Disease Prevention in Clinical Practice (constituted by representatives of nine societies and by invited experts). Atherosclerosis 223: 1-68.

Peters JL, Sutton AJ, Jones DR, Abrams KR, et al. (2006). Comparison of two methods to detect publication bias in metaanalysis. JAMA 295: 676-680.

Rhee EJ, Kwon CH, Lee WY, Kim SY, et al. (2007). No association of Pro12Ala polymorphism of PPAR-gamma gene with coronary artery disease in Korean subjects. Circ. J. 71: 338-342.

Ruiz-Narváez EA, Kraft P and Campos H (2007). Ala12 variant of the peroxisome proliferator-activated receptor-gamma gene (PPARG) is associated with higher polyunsaturated fat in adipose tissue and attenuates the protective effect of polyunsaturated fat intake on the risk of myocardial infarction. Am. J. Clin. Nutr. 86: 1238-1242.

Shi HB, Zhao WS, Luo J, Yao DW, et al. (2014). Peroxisome proliferator-activated receptor gamma1 and gamma2 isoforms alter lipogenic gene networks in goat mammary epithelial cells to different extents. J. Dairy Sci. 97: 5437-5447.

Smith SC Jr, Collins A, Ferrari R, Holmes DR Jr, et al. (2012). Our time: a call to save preventable death from cardiovascular disease (heart disease and stroke). J. Am. Coll. Cardiol. 60: 2343-2348.

Tian C, Ye X, Zhang R, Long J, et al. (2013). Green tea polyphenols reduced fat deposits in high fat-fed rats via erk1/2PPARgamma-adiponectin pathway. PLoS One 8: e53796.

Tobin MD, Braund PS, Burton PR, Thompson JR, et al. (2004). Genotypes and haplotypes predisposing to myocardial infarction: a multilocus case-control study. Eur. Heart J. 25: 459-467.

van Bilsen M and van Nieuwenhoven FA (2010). PPARs as therapeutic targets in cardiovascular disease. Expert Opin. Ther. Targets 14: 1029-1045.

Vogel U, Segel S, Dethlefsen C, Tjønneland A, et al. (2009). PPARgamma Pro12Ala polymorphism and risk of acute coronary syndrome in a prospective study of Danes. BMC Med. Genet. 10: 52.

Wahli W and Michalik L (2012). PPARs at the crossroads of lipid signaling and inflammation. Trends Endocrinol. Metab. 23: 351-363.

Wang LP, Zhao LR, Cui HW, Yan MR, et al. (2012). Association between PPARgamma2 Pro12Ala polymorphism and myocardial infarction and obesity in Han Chinese in Hohhot, China. Genet. Mol. Res. 11: 2929-2938.

Wang YX (2010). PPARs: diverse regulators in energy metabolism and metabolic diseases. Cell Res. 20: 124-137.

Wu Z, Lou Y, Jin W, Liu Y, et al. (2012). The Pro12Ala polymorphism in the peroxisome proliferator-activated receptor gamma-2 gene (PPARgamma2) is associated with increased risk of coronary artery disease: a meta-analysis. PLoS One 7: e53105.

Xu W, Xu J, Sun B, Chen H, et al. (2013). The effect of PPARG gene polymorphisms on the risk of coronary heart disease: a meta-analysis. Mol. Biol. Rep. 40: 875-884.

Yilmaz-Aydogan H, Kurnaz O, Kurt O, Akadam-Teker B, et al. (2011). Effects of the PPARG P12A and C161T gene variants on serum lipids in coronary heart disease patients with and without type 2 diabetes. Mol. Cell. Biochem. 358: 355-363.

Youssef SM, Mohamed N, Afef S, Khaldoun BH, et al. (2013). A Pro 12 Ala substitution in the PPARgamma2 polymorphism may decrease the number of diseased vessels and the severity of angiographic coronary artery. Coron. Artery Dis. 24 : 347-351.

Zee RY, Cook NR, Cheng S, Erlich HA, et al. (2006). Multi-locus candidate gene polymorphisms and risk of myocardial infarction: a population-based, prospective genetic analysis. J. Thromb. Haemost. 4: 341-348.

Zintzaras E and loannidis JP (2005). Heterogeneity testing in meta-analysis of genome searches. Genet. Epidemiol. 28: $123-137$. 